\section{BRAZIULIAN JOURNAL \\ OF MEDICAL AND BIOLOGICAL RESHARCH}

www.bjournal.com.br
ISSN 0100-879X

Volume 43 (11) 1010-1134 November 2010

BIOMEDICAL SCIENCES

AND

CLINICAL INVESTIGATION

Braz J Med Biol Res, November 2010, Volume 43(11) 1127-1134

doi: 10.1590/S0100-879X2010007500118

Longitudinal evaluation of hepatic osteodystrophy in children and adolescents with chronic cholestatic liver disease

A.T.A. Taveira, F.A. Pereira, M.I.M. Fernandes, R. Sawamura, M.H. Nogueira-Barbosa and F.J.A.

Paula

The Brazilian Journal of Medical and Biological Research is partially financed by

Q QNCNPq

Ministério Conselho Nacional de Dese
Cientifico e Tecnológico

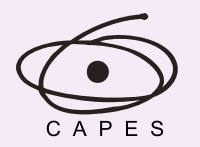

Ministério da Educação

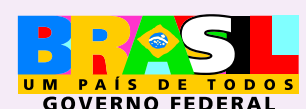

GOVERNO FEDERAL
DTAPESP

Institutional Sponsors
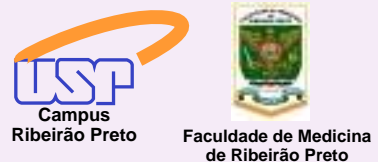

Ф SHIMADZU

GE Healthcare
Hotsite of proteomics metabolomics developped by:

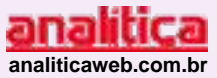

Thermo
ScIEN TIFIC 


\title{
Longitudinal evaluation of hepatic osteodystrophy in children and adolescents with chronic cholestatic liver disease
}

\author{
A.T.A. Taveira ${ }^{1}$, F.A. Pereira ${ }^{2}$, M.I.M. Fernandes ${ }^{1}$, R. Sawamura ${ }^{1}$, \\ M.H. Nogueira-Barbosa ${ }^{2}$ and F.J.A. Paula ${ }^{2}$ \\ 1Departamento de Pediatria, ${ }^{2}$ Departamento de Clínica Médica, \\ Faculdade de Medicina de Ribeirão Preto, Universidade de São Paulo, \\ Ribeirão Preto, SP, Brasil
}

\begin{abstract}
Bone mass loss is a major complication of chronic cholestatic liver disease (CCD). However, the long-term impact of CCD on bone mass acquisition is unknown. We longitudinally assessed bone mineral density (BMD) and factors involved in bone remodeling in 9 children and adolescents with CCD Child-Pugh A ( 5 boys/4 girls) and in 13 controls (6 boys/7 girls). The groups were evaluated twice, at baseline (T0) and after 3 years (T1), when osteocalcin, deoxypyridinoline, 25-hydroxyvitamin-D, parathyroid hormone, insulin-like growth factor-I (IGF-I), and BMD (L1-L4, proximal femur and total body) were determined. Serum levels of receptor activator for nuclear factor $\mathrm{kB}$ ligand (RANKL) and osteoprotegerin were measured only at T1. Lumbar spine BMD was reanalyzed twice: after adjustment for bone age and to compensate for the height factor. Volumetric density was also estimated mathematically in L2-L4. The BMD of L1-L4 was lower in the CCD group (Z-score at T0: control $=-1.2 \pm 0.8$ vs CCD = $-2.2 \pm 1.4, \mathrm{P}<0.05 ; \mathrm{T} 1$ : control $=-0.7 \pm 0.8$ vs $\mathrm{CCD}=-2.1 \pm 1.1, \mathrm{P}<0.05)$. Osteocalcin and deoxypyridinoline were similar for the two groups. The CCD group presented lower IGF-I (Z-score at T1: control $=1.4 \pm 2.8$ vs CCD $=-1.5 \pm 1.0, P<0.05)$ and RANKL (control $=0.465 \pm 0.275$ vs CCD $=0.195 \pm 0.250 \mathrm{pM}, \mathrm{P}<0.05$ ) than control. Children with compensated CCD ChildPugh A showed early impairment of bone acquisition, with the impact being more severe in an initial phase and then tapering in a slowly progressive way. Reduction in endocrine IGF-I has a crucial role in this process.
\end{abstract}

Key words: Hepatic osteodystrophy; Insulin-like growth factor-I; Osteoporosis; Bone mineral density; Bone remodeling

\section{Introduction}

Hepatic osteodystrophy is one of the most important extra-liver expressions of chronic hepatic disease and represents the final result of several mechanisms contributing to bone fragility. The most relevant factors are nutritional changes, hormonal disorders and the metabolic environment inherent to the progressive deterioration of liver function (1-4). Regarding this last factor, cholestasis is used as a specific indicator determining bone involvement in chronic liver disease (5).

Although hepatic osteodystrophy may involve two osteometabolic disorders, osteoporosis and osteomalacia, over the last few years, evidence indicates that osteoporosis is the most important component of this disorder $(6,7)$. We recently observed that, even in the early stage of chronic cholestatic disease (CCD), bone mass development is impaired in children (8). However, the design of the previous study was cross-sectional and therefore unsuitable for evaluating the evolution of bone mass of patients with this disease.

Recently, the receptor activator for nuclear factor $\mathrm{kB}$ (RANK), its ligand (RANKL) and osteoprotegerin (OPG), which belong to the tumor necrosis factor (TNF) and TNF receptor superfamily, have emerged as a major molecular mechanism by which the osteoblasts modulate the activity of the osteoclasts. Stimulators of bone resorption increase RANKL expression in osteoblasts, and some also decrease OPG expression $(9,10)$. However, the relevance of serum RANKL and OPG levels has been questioned since it seems that the circulatory levels of these factors do not reflect the condition of the tissue microenvironment (11). Unexpectedly,

Correspondence: F.J.A. Paula, Departamento de Clínica Médica, FMRP, USP, Av. Bandeirantes, 3900, 14049-900 Ribeirão Preto, SP, Brasil. Fax: +55-16-3633-6695. E-mail: fjpaula@fmrp.usp.br

Received February 8, 2010. Accepted October 7, 2010. Available online October 29, 2010. Published November 12, 2010. 
high OPG levels have been found to be correlated with age and were significantly higher in osteoporotic women compared to age-matched controls (11). However, there are few studies in the literature regarding the role of serum RANKL/ OPG in children and, until today, there are no data about these factors in children with cholestatic liver disease.

The present study was conducted to determine the evolution of hepatic osteodystrophy in pediatric subjects by assessing: 1) possible changes in mineral metabolism by biochemical determination of serum calcium, phosphorus, magnesium, 25-hydroxyvitamin D (25-OH-D), and parathyroid hormone (PTH) levels; 2 ) bone mineral density (BMD) and biochemical bone remodeling parameters such as osteocalcin and deoxypyridinoline (DPD), and 3) the pattern of endocrine insulin-like growth factor-I (IGF-I) levels and their influence on the progression of this bone disorder. In addition, in the second evaluation we assessed the serum levels of osteoprotegerin/RANKL.

\section{Material and Methods}

The study was approved by the Ethics Committee of Faculdade de Medicina de Ribeirão Preto, Universidade de São Paulo (Protocol \#6974/05). Parents or persons legally responsible for the children gave written informed consent for participation in this study.

In our first study conducted in 2004-2005, we evaluated 36 children and adolescents, 13 of them with CCD (77\% with low bone mass) and 23 controls (8). Of the 23 control subjects, 10 moved to other addresses. Most of these individuals are children of migrant rural workers, a fact that prevented us from locating them, with 13 control subjects being left in the study. Of the 13 CCD children, 4 were excluded ( 2 of them died during the observation period, 1 was submitted to hepatic transplantation and 1 could not be located), leaving 9 CCD subjects. The present study corresponds to a reevaluation of the remaining group 3 years later ( $\mathrm{T} 1)$. The basal period ( $\mathrm{T} 0$ ) contemplates only results of those individuals able to participate in the second evaluation. Thus, in the current study the CCD group consisted of 9 children and adolescents, 5 boys and 4 girls with a mean age of $10.0 \pm 5.5$ years and a median age of 9.7 years. The etiology of liver disease was extrahepatic bile duct atresia in 5 individuals, ductal hypoplasia in 2, choledochous cyst in 1, and Alagille syndrome in 1. The severity of liver disease for all patients was classified as Child-Pugh A. The control group consisted of 13 healthy children and adolescents, 6 boys and 7 girls with a mean age of $10.6 \pm 3.2$ years and a median of 8.4 years and with normal height for age (Table 1). The control individuals had no personal history of metabolic disease, acute or chronic disorders, and were not taking any drugs interfering with bone and mineral metabolism. They were recruited at the Puericulture Outpatient Clinic of the Medical Center of Vila Lobato, FMRP, Ribeirão Preto, among those routinely fol- lowed up for pediatric medical care.

The diagnosis of CCD was based on clinical criteria (history of cholestatic liver disease of more than 6 months duration) and/or a liver biopsy. CCD patients were treated daily with an oral polyvitamin supplement (1000 IU ergocalciferol, $5000 \mathrm{IU}$ vitamin A, $80 \mathrm{mg}$ vitamin C, and $15 \mathrm{mg}$ vitamin $\mathrm{E}$ ) and also with parenteral vitamin $\mathrm{K}$ replacement at 15- to 30-day intervals depending on prothrombin time. These patients were being followed at the outpatient clinic of Pediatric Gastroenterology, Centro Médico Universitário, Faculdade de Medicina de Riberirão Preto, USP.

Children with osteometabolic disease not related to liver disease and those taking medications affecting bone mineral metabolism (estrogens, corticosteroids, diuretics, anticonvulsants) were excluded. All children admitted to the study had normal kidney function.

A peripheral blood sample was collected after an overnight fast and immediately processed to obtain serum and aliquots were stored in a freezer at $-70^{\circ} \mathrm{C}$. A sample of the second void urine was collected under standardized conditions at 8:00-9:00 am. An aliquot was immediately used for creatinine determination and a second one was stored frozen at $-70^{\circ} \mathrm{C}$. Liver function was evaluated by the following biochemical tests: alanine aminotransferase (ALT; normal range $(\mathrm{NR})=0-44 \mathrm{U} / \mathrm{L})$, aspartate aminotransferase (AST; $\mathrm{NR}=0-34 \mathrm{U} / \mathrm{L})$, alkaline phosphatase (NR = 65-650 U/L), gamma-glutamyltransferase ( $\mathrm{YGT}$; NR $=7-50 \mathrm{U} / \mathrm{L})$, albumin $(\mathrm{NR}=35-50 \mathrm{~g} / \mathrm{L})$, total protein $(\mathrm{NR}=40-60 \mathrm{~g} / \mathrm{L})$, total bilirubin $(\mathrm{NR}=0.0-20.52 \mu \mathrm{M})$, and direct bilirubin $(\mathrm{NR}=0.0-5.13$ $\mu \mathrm{M})$. The analyses were performed using an automatic biochemical analyzer (KoneLab 60, WINER, Argentina). The prothrombin test (NR = 10.1-13.7 s) was also performed, with determination of the international normalized ratio by the clotting test using an automatic analyzer (STA Compact, Stago, USA). The Child-Pugh criterion modified for chronic cholestasis was used for the classification of the severity of chronic liver disease (12).

Serum levels of total calcium $(\mathrm{NR}=2.12-2.62 \mathrm{mM})$ and inorganic phosphorus were assessed with an automatic biochemical analyzer (Dimension RXL, Dade-Behring, USA). The serum levels of magnesium were determined by atom absorption spectrophotometry (Perkin Elmer Apparatus, USA). Osteocalcin was measured by an immunoradiometric (IRMA) method (DSL-7600, USA). Urinary DPD was measured by an immunoenzymatic (ELISA) assay (Metra, USA). The intra-assay coefficient of variation (CV) for osteocalcin and DPD was 3.3 and $2.1 \%$, respectively. Serum $25-\mathrm{OH}-\mathrm{D}$ was measured by radioimmunoassay (DiaSorin, Italy), CV $=6.1 \%$. Serum PTH was measured by chemoluminescence (Diagnostic Products Corporation, USA), CV $=3.2 \%$, and IGF-I was measured by IRMA (DSL-5600, Diagnostic Systems Laboratories, USA), CV $=9.6 \%$. OPG and RANKL were determined by ELISA (Biomedica, Austria) with an intra-assay CV of 2.3 and $4.4 \%$, respectively.

Scans of lumbar spine (L1-L4), total hip and femoral 
neck BMD, as well as total body lean and fat mass were determined by double-energy X-ray emission (Hologic $4500 \mathrm{~W}, \mathrm{USA}$ ). The exams were performed according to rigid positioning criteria standardized for each target site, by the same operator. BMD results are reported as areal BMD $\left(\mathrm{g} / \mathrm{cm}^{2}\right)$ and Z-score. The Z-score was re-evaluated, taking into account adjustment for bone age. In addition, volumetric density of the lumbar spine (aBMD) was also estimated mathematically in L2-L4 as proposed by Carter et al. (13), using the following equation: $a B M D=\alpha / \beta$, where $\alpha$ is BMD (in $\mathrm{g} / \mathrm{cm}^{2}$ ) of the lumbar spine (L2-L4) and $\beta$ is the square root of bone area (in $\mathrm{cm}^{2}$ ) of the lumbar spine (L2-L4).

The precision errors of BMD measurements were 1.2\% for the lumbar spine (L1-L4), 1.9\% for the femoral neck, and $2.9 \%$ for the total femur. Low BMD was defined using the criteria of the International Society of Clinical Densitometry, i.e, a Z-score of -2.0 or less adjusted for age and gender (14). Bone age was determined by the method of GraulichPyle, as described (8).

Laboratory and BMD data were analyzed statistically by the Multilevel test (random and fixed effects) and regression models were constructed using the PROC MIXED software (SAS version 8.0, USA). The standard deviation score of IGF-I, expected values for age, was calculated according to manufacturer information. Data regarding the comparison of alkaline phosphatase, BMD, bone mineral content (BMC), lean mass and fat mass at T0 and T1 in each subject were analyzed by the parametric paired Student $t$-test. (15).

\section{Results}

The clinical characteristics of both groups are given in Table 1. There were no significant differences in age, weight or height between groups at T0 and T1. However, when height was expressed as a Z-score, the values were significantly higher in the control group at both evaluations.

Serum albumin levels were normal in both groups, but the values were higher in the control group than in the CCD group at both T0 and T1 (Table 1). The serum levels of liver enzymes (AST, ALT, yGT, and alkaline phosphatase) were higher in the CCD group than in the control group at T0 and T1, although serum AST and ALT levels decreased from T0 to T1. A different pattern was observed regarding serum levels of alkaline phosphatase, since both groups presented higher serum levels at the last evaluation (Table 1). The patients with cholestasis showed lower serum magnesium levels than the control group at T1.

Both groups showed normal serum levels of 25-OH-D during the study. Vitamin $D$ values were higher in the CCD group compared to the control group at first evaluation, but this difference was no longer observed at T1. Only one CCD patient presented vitamin D deficiency (serum level $<25.0 \mathrm{nM}$ ). Serum PTH levels were similar for the two groups at the first evaluation, but increases of 87 and $47 \%$ were observed in the CCD and control group, respectively, at the second evaluation. Thus, at T1, the serum levels of PTH were significantly higher in the CCD group $(7.9 \pm$ $3.5 \mathrm{pM})$ compared to the control group $(5.0 \pm 2.2 \mathrm{pM}$; $\mathrm{P}<$ 0.05 ; Table 1).

The parameters of bone remodeling, i.e., osteocalcin and urinary DPD, were similar for the two groups at T0. The control group showed a stronger tendency to an increase in serum osteocalcin levels, but there were no differences between groups at the end of the study. Only the CCD group showed a tendency to an increase in the urinary levels of DPD at T1 (Table 1).

Serum OPG levels were similar for the two groups. Circulating RANKL levels were significantly lower in the CCD group $(0.2 \pm 0.2 \mathrm{pM})$ as compared to the control group $(0.4 \pm 0.2 \mathrm{pM} ; \mathrm{P}<0.05)$ and the OPG/RANKL ratio was significantly higher in the CCD group (Table 1).

The control group showed higher serum IGF-I levels than the cholestatic patients, with values being significantly higher at T1 (control $=64.1 \pm 44.9$ vs CCD $=19.8$ $\pm 24.1 \mathrm{nM} ; \mathrm{P}<0.05)$. In addition, when IGF-I levels were expressed as Z-score, the values were significantly higher in the control group than in the CCD group at both TO and T1 (Figure 1).

At T1, both groups showed a significant increase in BMD and BMC of the lumbar spine [e.g., BMC: CCD (T0 $=14.9 \pm 9.9$ and $\mathrm{T} 1=20.2 \pm 11.4 \mathrm{~g} ; \mathrm{P}<0.05)$ vs control $(\mathrm{T} 0=20.4 \pm 11.2$ and $\mathrm{T} 1=29.3 \pm 13.7 \mathrm{~g} ; \mathrm{P}<0.05)$. The increase corresponded to 35.6 and $43.6 \%$ in the CCD and control groups, respectively. The Z-score values of the lumbar spine were significantly higher in the control group at T0 (control $=-1.2 \pm 0.8$ vs CCD $=-2.2 \pm 1.4 ; \mathrm{P}<$ 0.05 ) and T1 (control $=-0.7 \pm 0.8$ vs $\mathrm{CCD}=-2.1 \pm 1.1 ; \mathrm{P}$ $<0.05)$. The pattern of the bone Z-score was maintained when the bone age of both groups was considered (TO: control $=-0.9 \pm 1.0$ vs $\mathrm{CCD}=-2.3 \pm 0.9 ; \mathrm{P}<0.05$ and $\mathrm{T} 1$ : control $=-1.0 \pm 0.6$ vs $C C D=-1.8 \pm 0.9 ; P<0.05)$. In the first evaluation, $77.7 \%$ of the CCD group and $15.3 \%$ of the control group presented low bone mass (Z-score $\leq 2.0)$. At $\mathrm{T} 1$, the rate of low bone mass was $0 \%$ for the control group and $66 \%$ for the CCD group. The estimated aBMD tended to increase in the control group (TO $=0.106 \pm 0.022$ and $\left.\mathrm{T} 1=0.109 \pm 0.017 \mathrm{~g} / \mathrm{cm}^{3}\right)$ and to decrease in the CCD group $\left(\mathrm{T} 0=0.099 \pm 0.021\right.$ and $\left.\mathrm{T} 1=0.095 \pm 0.022 \mathrm{~g} / \mathrm{cm}^{3}\right)$. Although aBMD values were higher in the control group at both times (T0 and T1), the differences between groups were not significant.

Total hip and femoral neck BMD values did not differ between groups at T0. An increase in these parameters, which was more evident in the control group, was observed during the study period. Thus at T1, the values of femoral neck BMD were significantly higher in the control group than in the CCD group (control $=0.753 \pm 0.11$ vs CCD $=0.597$ $\pm 0.121 \mathrm{~g} / \mathrm{cm}^{2} ; \mathrm{P}<0.05$; Table 2). Total hip BMD was not significantly higher in the control group compared to the 
CCD group (Table 2).

Lean mass, fat mass and fat percent were slightly higher in the control group than in the CCD group at T0 and T1. Lean mass increased by $32.9 \%$ in the CCD group (T0 = $16383.8 \pm 9150.2$ vs $\mathrm{T} 1=21782.9 \pm 10883.9 \mathrm{~g} ; \mathrm{P}<0.05)$ and by $43.4 \%$ in the control group (T0 $=18133.2 \pm 6390.8$ $\mathrm{g}$ vs $\mathrm{T} 1=26009.9 \pm 7667.8 \mathrm{~g} ; \mathrm{P}<0.05)$ while fat mass increased by $63.3 \%$ in the control group (T0 $=6136.6 \pm$ $4757.2 \mathrm{~g}$ vs $\mathrm{T} 1=10024.0 \pm 4322.0 \mathrm{~g} ; \mathrm{P}<0.05)$ and by $16 \%(\mathrm{TO}=6300.7 \pm 6979.0$ vs T1 $=7329.2 \pm 5797.6 \mathrm{~g} ; \mathrm{P}$ $=0.17)$ in the CCD group. Compared to T0, percent body fat decreased by $5.3 \%$ in the CCD group and increased by $14.4 \%$ in the control group at T1 (Table 2).

Both groups presented a positive correlation between IGF-I and BMD. This was observed in the CCD group in the total body (T0: $r=0.740, P<0.05$ and T1: $r=0.586, P<$ 0.05), lumbar spine (T1: $r=0.675, P<0.05$ ), total hip (T0: $r$ $=0.759, \mathrm{P}<0.05$ and T1: $\mathrm{r}=0.759, \mathrm{P}<0.05)$, and femoral neck (T0: $r=0.779, P<0.05$ and T1: $r=0.799, P<0.05$ ) and in the control group in the lumbar spine (T0: $r=0.76$, $P<0.05$ and T1: $r=0.56, P=0.05)$. In the control group and in the CCD group, the aBMD of the lumbar spine was

Table 1. Demographic characteristics and laboratory results of patients with chronic cholestatic disease (CCD) and the control group at first (T0) and second (T1) evaluations.

\begin{tabular}{|c|c|c|c|c|}
\hline & \multicolumn{2}{|c|}{ T0 } & \multicolumn{2}{|r|}{ T1 } \\
\hline & Control & CCD & Control & CCD \\
\hline CA (years) & $7.2 \pm 5.3$ & $7.6 \pm 3.4$ & $10.6 \pm 3.2$ & $10.0 \pm 5.5$ \\
\hline BA (years) & $6.7 \pm 5.6$ & $7.0 \pm 4.0$ & $10.7 \pm 3.4$ & $8.9 \pm 5.3$ \\
\hline Weight (kg) & $23.5 \pm 15.8$ & $26.0 \pm 10.3$ & $38.7 \pm 9.0$ & $30.0 \pm 16.7$ \\
\hline Height (cm) & $112.0 \pm 25.5$ & $125.4 \pm 16.4$ & $144.3 \pm 16.4$ & $126.8 \pm 20.5$ \\
\hline Z-score/height & $-1.2 \pm 0.7$ & $0.4 \pm 0.9^{*}$ & $0.4 \pm 0.9$ & $-1.1 \pm 0.9^{*}$ \\
\hline AST $(\mathrm{NR}=0.0-34.0 \mathrm{U} / \mathrm{L})$ & $44 \pm 41.7$ & $93.2 \pm 53.3^{*}$ & $23.8 \pm 6.2$ & $55.8 \pm 34.4^{*}$ \\
\hline ALT $(N R=0.0-44.0 \mathrm{U} / \mathrm{L})$ & $36.6 \pm 16.3$ & $97.3 \pm 46.6^{*}$ & $21 \pm 24.3$ & $44.1 \pm 24.3^{*}$ \\
\hline үGT $(\mathrm{NR}=7.0-50.0 \mathrm{U} / \mathrm{L})$ & $21.8 \pm 5.3$ & $171.4 \pm 134.2^{*}$ & $22.3 \pm 3.1$ & $77.9 \pm 68.2^{*}$ \\
\hline $\mathrm{AP}(\mathrm{NR}=65-650 \mathrm{U} / \mathrm{L})$ & $242.7 \pm 70.2$ & $530.0 \pm 250.8^{*+}$ & $638.9 \pm 209.0$ & $1115.5 \pm 748.0^{*+}$ \\
\hline $\mathrm{TP}(\mathrm{NR}=40-60 \mathrm{~g} / \mathrm{L})$ & $74 \pm 3$ & $73 \pm 6$ & $68 \pm 5$ & $68 \pm 4$ \\
\hline ALB $(\mathrm{NR}=35-50 \mathrm{~g} / \mathrm{L})$ & $46 \pm 2$ & $42 \pm 4^{*}$ & $43 \pm 2$ & $39 \pm 4^{*}$ \\
\hline TB $(\mathrm{NR}=0.0-20.52 \mu \mathrm{M})$ & & $29.0 \pm 39.3$ & & $30.7 \pm 32.4$ \\
\hline $\mathrm{DB}(\mathrm{NR}=0.0-5.13 \mu \mathrm{M})$ & & $18.8 \pm 35.9$ & & $13.6 \pm 17.1$ \\
\hline Bile acids & & & & $63.8 \pm 93.0$ \\
\hline $\mathrm{PT}(\mathrm{NR}=10.1-13.7 \mathrm{~s})$ & & $1.0 \pm 0.1$ & & $1.1 \pm 0.9$ \\
\hline $\mathrm{Ca}(\mathrm{NR}=2.12-2.62 \mathrm{mM})$ & $2.3 \pm 0.07$ & $2.3 \pm 0.07$ & $2.0 \pm 0.02$ & $2.3 \pm 0.17^{*}$ \\
\hline $\mathrm{Pi}(\mathrm{NR}=0.80-1.80 \mathrm{mM})$ & $1.5 \pm 0.19$ & $1.5 \pm 0.25$ & $1.7 \pm 0.16$ & $1.5 \pm 0.06$ \\
\hline $\mathrm{Mg}(\mathrm{NR}=0.53-0.88 \mathrm{mM})$ & $0.5 \pm 0.06$ & $0.5 \pm 0.03$ & $0.7 \pm 0.2$ & $0.5 \pm 0.16^{*}$ \\
\hline Osteocalcin (nM) & $41.3 \pm 10.2$ & $41.3 \pm 9.9$ & $72.8 \pm 38.6$ & $54.3 \pm 19.8$ \\
\hline DPD (nM creat.) & $28.7 \pm 30.3$ & $23.6 \pm 8.8$ & $28.3 \pm 10.4$ & $31.9 \pm 24.1$ \\
\hline Vitamin D (nM) & $43.0 \pm 8.3$ & $61.8 \pm 26.8^{*}$ & $56.0 \pm 31.0$ & $58.3 \pm 36.8$ \\
\hline PTH (NR = 1.15-7.05 pM) & $3.4 \pm 1.6$ & $4.2 \pm 1.8$ & $5.0 \pm 2.2$ & $7.9 \pm 3.5^{*}$ \\
\hline IGF-I (nM) & $19.9 \pm 18.6$ & $6.9 \pm 8.0$ & $64.1 \pm 44.9$ & $19.8 \pm 24.1^{*}$ \\
\hline OPG (pM) & & & $0.7 \pm 0.6$ & $0.6 \pm 0.3$ \\
\hline RANKL (pM) & & & $0.465 \pm 0.275$ & $0.195 \pm 0.250^{*}$ \\
\hline OPG:RANKL & & & $0.14 \pm 0.15$ & $0.39 \pm 0.3^{*}$ \\
\hline
\end{tabular}

$\mathrm{CA}=$ chronological age; $\mathrm{BA}=$ bone age; $\mathrm{AST}=$ aspartate aminotransferase; $\mathrm{NR}=$ normal range; $\mathrm{ALT}=$ alanine aminotransferase; $\mathrm{YGT}=\mathrm{y}$-glutamyltransferase; $\mathrm{AP}=$ alkaline phosphatase; $\mathrm{TP}=$ total protein; $\mathrm{ALB}$ = albumin; $\mathrm{TB}=$ total bilirubin; $\mathrm{DB}=$ direct bilirubin; $\mathrm{PT}=$ prothrombin time; $\mathrm{Ca}=$ calcium; $\mathrm{Pi}=$ phosphorus; $\mathrm{Mg}=$ magnesium; DPD = urinary deoxypyridinoline; $\mathrm{PTH}=$ parathormone; IGF-I = insulin-like growth factorI; OPG = osteoprotegerin; RANKL = receptor activator for nuclear factor $\mathrm{kB}$ ligand. ${ }^{*} \mathrm{P}<0.05$ compared to control [multilevel test (random and fixed effects)]. ${ }^{+} \mathrm{P}<0.05$ compared to T0 of the same group (parametric paired Student $t$-test). 
also positively correlated to IGF-I (T0: $r=0.769, \mathrm{P}<0.05$ ) (T1: $r=0.700, P<0.05)$, respectively. We did not detect a correlation of serum bilirubin, bile acid, PTH, vitamin D, or osteocalcin with BMD at T0 or T1 in either group. There was a positive correlation between the OPG:RANKL ratio and serum DPD levels in the CCD group $(r=0.717, P<0.05)$, whereas no correlation was observed between RANKL or OPG levels and bone densitometry measurements.

\section{Discussion}

The risk of fracture for adults of any population is determined by the interaction between genetic and environmental factors throughout life and mainly depends on factors limiting peak bone mass. Genetic factors determine 60 to $80 \%$ of the variation in bone mass (16). However, environmental factors such as nutrition, life style and systemic diseases may also have a significant effect on this process (17). The etiopathogeny of hepatic osteodystrophy is not fully understood. During the terminal phase of slowly progressive liver disease, hepatic osteodystrophy is the result of a set of factors that are being incorporated along the process of declining hepatic function $(2,18)$ : a) nutritional factors (anorexia, weight loss, changes in body composition, and vitamin $\mathrm{D}$ deficiency) (18); b) hormonal factors (hypogonad- ism (18), vitamin D (17) and IGF-I deficiencies (8,18); c) metabolic alterations typical of hepatic insufficiency (acidbase disequilibrium, disorders of intermediate metabolism, and cholestasis) (18), and d) inflammatory state (production of cytokines and interleukins) (19). The present study shows

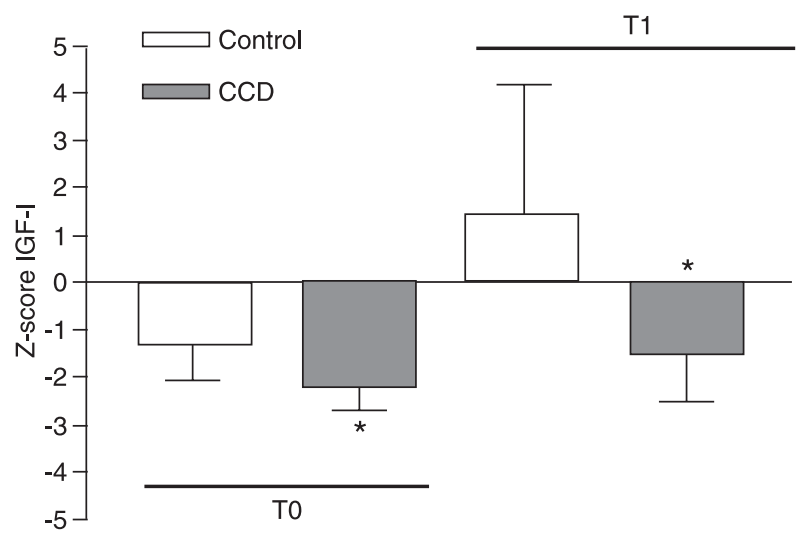

Figure 1. Insulin-like growth factor-I (IGF-I) Z-scores for the control group and for the group of individuals with chronic cholestatic disease (CCD) at first (T0) and second (T1) evaluations. ${ }^{*} \mathrm{P}<0.05$ compared to the control group (multilevel test, random and fixed effects).

Table 2. Bone mineral density of the lumbar spine of patients with chronic cholestatic disease (CCD) and the control group at the first (T0) and second evaluations (T1).

\begin{tabular}{|c|c|c|c|c|}
\hline & \multicolumn{2}{|c|}{ T0 } & \multicolumn{2}{|c|}{$\mathrm{T} 1$} \\
\hline & Control & CCD & Control & CCD \\
\hline \multicolumn{5}{|l|}{ Lumbar spine } \\
\hline BMD $\left(\mathrm{g} / \mathrm{cm}^{2}\right)$ & $0.549 \pm 0.159$ & $0.461 \pm 0.158$ & $0.663 \pm 0.157^{+}$ & $0.545 \pm 0.165^{+}$ \\
\hline $\mathrm{BMC}(\mathrm{g})$ & $20.4 \pm 11.2$ & $14.9 \pm 9.9$ & $29.3 \pm 13.7^{+}$ & $20.2 \pm 11.4^{+}$ \\
\hline Z-score & $-1.2 \pm 0.8$ & $-2.2 \pm 1.4^{*}$ & $-0.7 \pm 0.8$ & $-2.1 \pm 1.1^{*}$ \\
\hline Z-score/BA & $-0.9 \pm 1.0$ & $-2.3 \pm 0.9^{*}$ & $-1.0 \pm 0.6$ & $-1.8 \pm 0.9^{*}$ \\
\hline BMD vol. $\left(\mathrm{g} / \mathrm{cm}^{3}\right)$ & $0.106 \pm 0.022$ & $0.099 \pm 0.021$ & $0.109 \pm 0.017$ & $0.095 \pm 0.022$ \\
\hline \multicolumn{5}{|l|}{ Total hip } \\
\hline $\mathrm{BMD}\left(\mathrm{g} / \mathrm{cm}^{2}\right)$ & $0.669 \pm 0.133$ & $0.571 \pm 0.160$ & $0.768 \pm 0.135$ & $0.643 \pm 0.152$ \\
\hline \multicolumn{5}{|l|}{ Femoral neck } \\
\hline $\mathrm{BMD}\left(\mathrm{g} / \mathrm{cm}^{2}\right)$ & $0.659 \pm 0.114$ & $0.545 \pm 0.158$ & $0.753 \pm 0.11$ & $0.597 \pm 0.121^{*}$ \\
\hline \multicolumn{5}{|l|}{ Body composition } \\
\hline $\mathrm{BMD}\left(\mathrm{g} / \mathrm{cm}^{2}\right)$ & $0.703 \pm 0.096$ & $0.636 \pm 0.156$ & $0.775 \pm 0.088$ & $0.693 \pm 0.133$ \\
\hline $\mathrm{BMC}(\mathrm{g})$ & $875.7 \pm 375.7$ & $744.5 \pm 508.7$ & $1251.0 \pm 401.4$ & $978.1 \pm 537.8$ \\
\hline Lean mass & $18113.2 \pm 6390.8$ & $16383.8 \pm 9150.2$ & $26009.9 \pm 7667.8$ & $21782.9 \pm 10883.9$ \\
\hline Fat mass & $6136.6 \pm 4757.2$ & $6300.7 \pm 6979.0$ & $10024.0 \pm 4322.0$ & $7329.2 \pm 5797.6$ \\
\hline$\%$ Fat & $23.6 \pm 9.1$ & $24.5 \pm 7.9$ & $27 \pm 8.6$ & $23.2 \pm 6.5$ \\
\hline
\end{tabular}

$\mathrm{BMD}=$ bone mineral density per area; $\mathrm{BMC}=$ bone mineral content; $\mathrm{BA}=$ bone age; $\mathrm{BMD}$ vol. = $\mathrm{L} 2-\mathrm{L} 4$ volumetric BMD. ${ }^{*} \mathrm{P}<0.05$ compared to control (multilevel test, random and fixed effects). ${ }^{+} \mathrm{P}<0.05$ compared to T0 of the same group (parametric paired Student $t$-test). 
that long-term impairment of bone mass development occurs even in children with mild and functionally compensated hepatic disease. Additionally, our data indicate that chronic hepatic underproduction of IGF-I has a pivotal role in the limitation of bone mass accrual in CCD.

In a previous cross-sectional study, we observed that 10 of 13 children and adolescents $(77 \%)$ with Child-Pugh $A$ and $B$ cholestasis had a low bone mass for their ages in the lumbar spine (Z-score below -2.0). Furthermore, this pattern was maintained after the evaluation with adjustment for bone age and volumetric density. In the current study, 9 children were longitudinally evaluated, all of them classified as compensated Child-Pugh $A$ and it was observed that almost $70 \%$ presented low bone mass 3 years after the first evaluation. In contrast, of the 13 control subjects who were reevaluated about 3 years after the first assessment, all those who had low bone mass for their age developed a normal Z-score. The data show that the impairment of bone mass development in CCD is not due to delayed maturation. The CCD group presented lower bone mass than the control group, even after the BMD data were adjusted for bone age. In addition, in order to minimize the influence of bone size by the measurement of areal bone density, volumetric density was estimated mathematically in the lumbar spine. During the 3-year period, a trend to an increase in aBMD was observed in the control group as well as a decrease in the CCD group was observed. The control group presented a non-significantly higher volumetric lumbar BMD than the CCD group. Furthermore, the control group showed a tendency to an increase in volumetric BMD, whereas the CCD group exhibited a tendency to a decrease in volumetric lumbar spine density after 3 years.

In the present study, children and adolescents with cholestasis maintained a clinically compensated condition, with ALT, AST and YGT levels actually being lower at the last evaluation as compared to the initial levels. Nevertheless, the patients did not show recovery of bone mass. On the contrary, the data suggested a slower gain of bone mass compared to control, most likely implying a slow but progressive impairment of the accrual of peak bone mass.

No association between bilirubin levels and BMD was detected. These data contrast with in vitro studies demonstrating that serum with hyperbilirubinemia reduced the mitogenic activity of osteoblast-like cells (5). Some clinical studies also showed that osteoporosis is more frequent in cholestatic patients than in non-cholestatic patients with liver disease (18-20). However, the present data agree with previous clinical and experimental studies that did not detect an association between cholestasis and bone mass loss $(21,22)$. Possibly, hyperbilirubinemia impacts on bone mass development and maintenance when advanced hepatic dysfunction is established.

Although early studies have suggested that disorders of mineralization may be an important component of hepatic osteodystrophy (23-25), later studies did not reproduce these findings. Indeed, Long et al. (23) and Crosbie et al. (26) reported that treatment with vitamin D does not prevent the progression of hepatic osteodystrophy in adults. The present study shows that children and adolescents with CCD have a significant limitation of bone mass development even when their serum 25-OH-D levels are maintained within normal limits. In addition, an association between serum 25-OH-D levels and bone mass was not observed in these patients. During the study, the CCD patients showed a significant increase in serum PTH levels. In addition to the low calcium intake by these patients (27), another aspect to be considered is the possibility of increased PTH fragments detected by the second-generation PTH assays, which were used in the present study. The liver is an important site of peripheral PTH metabolism $(28,29)$, but PTH clearance in chronic liver disease has not been determined.

The RANK/RANKL/OPG system is a molecular link by which the osteoblasts modulate osteoclastogenesis and bone resorption $(30,31)$. The osteoblasts express the RANKL membrane receptor and thereby interact with RANK, present in pre-osteoclasts and osteoclasts, and then stimulate cell differentiation and osteolytic activity, respectively. In addition, the osteoblasts may produce OPG, which inactivates RANKL. The determination of circulating levels of soluble RANKL and OPG in situations of bone catabolism does not always reflect the pattern expected at the tissue level whereby the hyperexpression of RANKL leads to osteoporosis and the increased production of OPG prevents bone loss (32). Grigorie et al. (33) detected increased serum OPG levels in postmenopausal women with osteoporosis. In addition, there are data showing a negative correlation between serum OPG levels and forearm BMD (34). Regarding the measurement of soluble RANKL, there are published data showing that low serum RANKL levels are predictors of the risk of fracture (35).

In the present study, CCD children and adolescents presented OPG levels compatible with those detected in the control group, but their RANKL levels were significantly lower than control. Therefore, further studies are needed to determine if the reduction of serum RANKL levels in children may also indicate a greater risk for fracture, as was suggested for adults (35). Additionally, several factors that impair the interpretation of RANKL and OPG measurements should be considered (36). OPG is also produced in tissues such as the skin, stomach, intestine, lung, heart, and placenta. In addition, enzymatic assays detect several fragments of circulating OPG (36). The variables that may interfere with the determination of soluble RANKL range from the instability of the molecule itself to the influence of physiological factors such as the menstrual cycle, age and gender (36).

We observed a strong association between bone mass and serum IGF-I levels in a previous study of cholestatic children (8). The present data support these data indicating that the persistent reduction of hepatic IGF-I produc- 
tion seems to be a factor that perpetuates the impairment of bone mass development in cholestasis. It should be pointed out that a recent study using an experimental model demonstrated that, in hepatic cholestasis, not only serum IGF-I levels were low, but the expression of IGF-I and of the $\mathrm{GH}$ receptor was also reduced in tibial growth cartilage (22). Thus, it is possible that the impaired production not only of hepatic IGF-I, but also of IGF-I of the bone microenvironment (paracrine-autocrine) contributed to the onset of hepatic osteodystrophy. The importance of the endocrine and paracrine IGF-I system for the development and maintenance of bone mass has been demonstrated directly and indirectly in various experimental $(37,38)$ and clinical (39) models.

Thus, the present data indicate that cholestasis is a disease associated with the underdevelopment of bone mass in children and adolescents. This can be clearly seen when comparing the pattern of bone mass evolution of the control group to that of the CCD group. In the control group, while children with low bone mass at the first evalu-

\section{References}

1. Hay JE. Bone disease in cholestatic liver disease. Gastroenterology 1995; 108: 276-283.

2. Gasser RW. Cholestasis and metabolic bone disease - a clinical review. Wien Med Wochenschr 2008; 158: 553557.

3. Sylvester FA. An update on bone abnormalities associated with gastrointestinal and liver disease. Endocrinologist 2001; 11: 77-85.

4. Leslie WD, Bernstein CN, Leboff MS. AGA technical review on osteoporosis in hepatic disorders. Gastroenterology 2003; 125: 941-966.

5. Janes $\mathrm{CH}$, Dickson ER, Okazaki R, Bonde S, McDonagh AF, Riggs BL. Role of hyperbilirubinemia in the impairment of osteoblast proliferation associated with cholestatic jaundice. J Clin Invest 1995; 95: 2581-2586.

6. Argao EA, Specker BL, Heubi JE. Bone mineral content in infants and children with chronic cholestatic liver disease. Pediatrics 1993; 91: 1151-1154.

7. Ormarsdottir $\mathrm{S}$, Ljunggren $\mathrm{O}$, Mallmin $\mathrm{H}$, Michaelsson $\mathrm{K}$, Loof L. Increased rate of bone loss at the femoral neck in patients with chronic liver disease. Eur J Gastroenterol Hepatol 2002; 14: 43-48.

8. de Albuquerque Taveira AT, Fernandes MI, Galvao LC, Sawamura R, de Mello V, de Paula FJ. Impairment of bone mass development in children with chronic cholestatic liver disease. Clin Endocrinol 2007; 66: 518-523.

9. Rubin J, Ackert-Bicknell CL, Zhu L, Fan X, Murphy TC, Nanes MS, et al. IGF-I regulates osteoprotegerin (OPG) and receptor activator of nuclear factor-kappaB ligand in vitro and OPG in vivo. J Clin Endocrinol Metab 2002; 87: 4273-4279.

10. Blair JM, Zheng Y, Dunstan CR. RANK ligand. Int J Biochem Cell Biol 2007; 39: 1077-1081.

11. Yano K, Tsuda E, Washida N, Kobayashi F, Goto M, Harada ation progressed to densitometric bone mass normalization after three years, those of the CCD group continued to present a condition of low bone mass acquisition. The reduced production of hepatic IGF-I seemed to be one of the factors responsible for this occurrence. Further studies are needed to evaluate the significance of reduced serum RANKL levels and of the consequent increase in circulating OPG/RANKL levels.

\section{Acknowledgments}

We wish to thank Tania Maria Beltramini Trevillato (Departamento de Pediatria da Faculdade de Medicina de Ribeirão Preto, USP), Massako Sakai Kodama and Rita de Cássia C.V. Barbosa (Departamento de Clínica Médica da Faculdade de Medicina de Ribeirão Preto, USP) for efficient technical collaboration. Research supported by FAPESP (\#06/61394-2), and FAEPA (Fundação de Apoio ao Ensino Pesquisa e Assistência).
A, et al. Immunological characterization of circulating osteoprotegerin/osteoclastogenesis inhibitory factor: increased serum concentrations in postmenopausal women with osteoporosis. J Bone Miner Res 1999; 14: 518-527.

12. Sherlock S, Dooley J. Hepatic transplantation. In: Sherlock $\mathrm{S}$, Dooley J (Editors), Diseases of the liver and biliary system. 11th edn. Malden: Blackwell Science; 2002. p 657679.

13. Carter DR, Bouxsein ML, Marcus R. New approaches for interpreting projected bone densitometry data. J Bone Miner Res 1992; 7: 137-145.

14. Baim S, Leonard MB, Bianchi ML, Hans DB, Kalkwarf HJ, Langman CB, et al. Official Positions of the International Society for Clinical Densitometry and Executive Summary of the 2007 ISCD Pediatric Position Development Conference. $J$ Clin Densitom 2008; 11: 6-21.

15. Singer JD. Using SAS PROC MIXED to fit multilevel models, hierarchical models, and individual growth models. J Educ Behav Stat 1998; 24: 323-355.

16. Norris SA, Nelson D. Ethnic differences in bone acquisition. In: Rosen CJ (Editor), Primer on the metabolic bone diseases and disorders of mineral metabolism. Washington: American Society for Bone and Mineral Research; 2008. p 820-827.

17. Henwood MJ, Binkovitz L. Update on pediatric bone health. J Am Osteopath Assoc 2009; 109: 5-12.

18. Collier J. Bone disorders in chronic liver disease. Hepatology 2007; 46: 1271-1278.

19. van der Merwe SW, van den Bogaerde JB, Goosen C, Maree FF, Milner RJ, Schnitzler CM, et al. Hepatic osteodystrophy in rats results mainly from portasystemic shunting. Gut 2003; 52: $580-585$.

20. Guanabens N, Pares A, Ros I, Caballeria L, Pons F, Vidal $\mathrm{S}$, et al. Severity of cholestasis and advanced histological 
stage but not menopausal status are the major risk factors for osteoporosis in primary biliary cirrhosis. J Hepatol 2005; 42: $573-577$.

21. Newton J, Francis R, Prince M, James O, Bassendine M, Rawlings $\mathrm{D}$, et al. Osteoporosis in primary biliary cirrhosis revisited. Gut 2001; 49: 282-287.

22. Pereira FA, Facincani I, Jorgetti V, Ramalho LN, Volpon JB, Dos Reis LM, et al. Etiopathogenesis of hepatic osteodystrophy in Wistar rats with cholestatic liver disease. Calcif Tissue Int 2009; 85: 75-83.

23. Long RG, Meinhard E, Skinner RK, Varghese Z, Wills MR, Sherlock S. Clinical, biochemical, and histological studies of osteomalacia, osteoporosis, and parathyroid function in chronic liver disease. Gut 1978; 19: 85-90.

24. Compston JE, Thompson RP. Intestinal absorption of 25-hydroxyvitamin $\mathrm{D}$ and osteomalacia in primary biliary cirrhosis. Lancet 1977; 1: 721-724.

25. Reed JS, Meredith SC, Nemchausky BA, Rosenberg IH, Boyer JL. Bone disease in primary biliary cirrhosis: reversal of osteomalacia with oral 25-hydroxyvitamin D. Gastroenterology 1980; 78: 512-517.

26. Crosbie OM, Freaney R, McKenna MJ, Hegarty JE. Bone density, vitamin $\mathrm{D}$ status, and disordered bone remodeling in end-stage chronic liver disease. Calcif Tissue Int 1999; 64: $295-300$

27. Duarte MP, Farias ML, Coelho HS, Mendonca LM, Stabnov LM, do Carmo M, et al. Calcium-parathyroid hormone-vitamin $\mathrm{D}$ axis and metabolic bone disease in chronic viral liver disease. J Gastroenterol Hepatol 2001; 16: 1022-1027.

28. Segre GV, D'Amour P, Hultman A, Potts JT Jr. Effects of hepatectomy, nephrectomy, and nephrectomy/uremia on the metabolism of parathyroid hormone in the rat. $J$ Clin Invest 1981; 67: 439-448.

29. Martin K, Hruska K, Greenwalt A, Klahr S, Slatopolsky E. Selective uptake of intact parathyroid hormone by the liver: differences between hepatic and renal uptake. J Clin Invest 1976; 58: 781-788.
30. Raisz LG. Pathogenesis of osteoporosis: concepts, conflicts, and prospects. J Clin Invest 2005; 115: 3318-3325.

31. Boyce BF, Xing L. Functions of RANKL/RANK/OPG in bone modeling and remodeling. Arch Biochem Biophys 2008; 473: 139-146.

32. Hofbauer LC, Khosla S, Dunstan CR, Lacey DL, Spelsberg TC, Riggs BL. Estrogen stimulates gene expression and protein production of osteoprotegerin in human osteoblastic cells. Endocrinology 1999; 140: 4367-4370.

33. Grigorie D, Neacsu E, Marinescu M, Popa O. Circulating osteoprotegerin and leptin levels in postmenopausal women with and without osteoporosis. Rom J Intern Med 2003; 41: 409-415.

34. Jorgensen HL, Kusk P, Madsen B, Fenger M, Lauritzen JB. Serum osteoprotegerin (OPG) and the A163G polymorphism in the OPG promoter region are related to peripheral measures of bone mass and fracture odds ratios. $J$ Bone Miner Metab 2004; 22: 132-138.

35. Schett G, Kiechl S, Redlich K, Oberhollenzer F, Weger S, Egger $\mathrm{G}$, et al. Soluble RANKL and risk of nontraumatic fracture. JAMA 2004; 291: 1108-1113.

36. Vega D, Maalouf NM, Sakhaee K. CLINICAL Review \#: the role of receptor activator of nuclear factor-kappaB (RANK)/ RANK ligand/osteoprotegerin: clinical implications. J Clin Endocrinol Metab 2007; 92: 4514-4521.

37. Yakar S, Rosen CJ. From mouse to man: redefining the role of insulin-like growth factor-I in the acquisition of bone mass. Exp Biol Med 2003; 228: 245-252.

38. Yakar S, Rosen CJ, Beamer WG, Ackert-Bicknell CL, Wu Y, Liu JL, et al. Circulating levels of IGF-1 directly regulate bone growth and density. J Clin Invest 2002; 110: 771-781.

39. de Paula FJ, Gois-Junior MB, Aguiar-Oliveira MH, Pereira FA, Oliveira CR, Pereira RM, et al. Consequences of lifetime isolated growth hormone $(\mathrm{GH})$ deficiency and effects of short-term GH treatment on bone in adults with a mutation in the GHRH-receptor gene. Clin Endocrinol 2009; 70: 35-40. 